\title{
Surface Temperature Gradients as Diagnostic Indicators of Midlatitude Circulation Dynamics
}

\author{
CHRISTINA KARAMPERIDOU \\ Columbia University, New York, New York \\ FRANCESCO CIOFFI \\ University of Rome “La Sapienza,” Rome, Italy \\ UPMANU LALL \\ Columbia University, New York, New York
}

(Manuscript received 1 February 2011, in final form 22 November 2011)

\begin{abstract}
Zonal and meridional surface temperature gradients are considered to be determinants of large-scale atmospheric circulation patterns. However, there has been limited investigation of these gradients as diagnostic aids. Here, the twentieth-century variability in the Northern Hemisphere equator-to-pole temperature gradient (EPG) and the ocean-land temperature contrast (OLC) is explored. A secular trend in decreasing EPG and OLC is noted. Decadal and interannual (ENSO-related) variations in the joint distribution of EPG and OLC are identified, hinting at multistable climate states that may be indigenous to the climate or due to changing boundary forcings. The NH circulation patterns for cases in the tails of the joint distribution of EPG and OLC are also seen to be different. Given this context, this paper extends past efforts to develop insights into jet stream dynamics using the Lorenz-1984 model, which is forced directly and only by EPG and OLC. The joint probability distribution of jet stream and eddy energy, conditional on EPG and OLC scenarios, is investigated. The scenarios correspond to (i) warmer versus colder climate conditions and (ii) polarized ENSO phases. The latter scenario involves the use of a heuristic ENSO model to drive the Lorenz-1984 model via a modulation of the EPG or the OLC. As with GCMs, the low-order model reveals that the response to El Niño forcing is not similar to an anthropogenic warming signature. The potential uses of EPG and OLC as macro-level indicators of climate change and variability and for comparing results across GCMs and observations are indicated.
\end{abstract}

\section{Introduction}

The midlatitude storm track is a factor in determining moisture and heat transport associated with enhanced precipitation events. In a seminal paper, Lorenz (1984) developed a model-the Lorenz-1984 (L84)— for the jet stream and the superposed eddies that are forced by the equator-to-pole temperature gradient (EPG) and the ocean-land temperature contrast (OLC). The model exhibits chaos and intransitivity, depending on

Corresponding author address: Christina Karamperidou, Department of Earth and Environmental Engineering, Columbia University, 918 S. W. Mudd Hall, 500 West 120th Street, New York, NY 10027.

E-mail: ck2424@columbia.edu the combination of the EPG and OLC, and its properties have been extensively investigated parametrically by a number of authors (e.g., Lorenz 1990; Broer et al. 2002; Freire et al. 2008). In the L84 model (see the appendix), the EPG is a primary driver of the mean jet stream and the OLC of the eddies coupled to it. Nonlinear interactions between the jet stream and the eddies lead to complex behavior that depends on both the forcing parameters and past states of the system. Since the driving variables of this model are the EPG and OLC, the investigation of the trends and the decadal and interannual regimes of these variables may be of primary interest for understanding the nature of the midlatitude storm track.

To the authors' knowledge, only one paper, namely, Jain et al. (1999), has investigated twentieth-century 
observations of the forcing variables EPG and OLC. Jain et al. (1999) study the trends, the seasonality and interannual variability of the observed equator-to-pole gradient and ocean-land contrast in the period 1900-90, and examine their response to increased greenhouse gas emissions in a GCM. The first part of this paper extends that work to (i) look at changes in the joint probability distribution of EPG and OLC over the last century, focusing on decadal variations and ENSO-related changes; and (ii) qualitatively examine changes in the Northern Hemisphere midlatitude jet stream and storm track for extreme combinations of EPG and OLC.

Motivated by the fact that the combination of the EPG and OLC parameters in the L84 model is what gives rise to different solutions in the phase space, our focus is on their joint variability in the record, in addition to the trends in the individual variables. Using temperature data updated since the work of Jain et al. (1999), to construct the Northern Hemisphere EPG and OLC, we find that there is a statistically significant shift toward decreased values for both EPG and OLC and their combination. The midlatitude storm track and the continental jet entry and exit locations are shifted in years corresponding to opposite extreme combinations of EPG and OLC. An examination of how the joint probability distribution of EPG and OLC varies in 20-yr increments over the twentieth century reveals statistically significant decadal variations in addition to the secular trend.

The joint probability density function (pdf) of EPG and OLC during El Niño events is found to be distinct from the one during La Niña and neutral states. Further, the cross-correlation function between OLC and the Niño-3 index reflects the observed and modeled changes in eddy-driven circulation during ENSO events. The databased analyses of the potential forcing of EPG and OLC by ENSO reveal a stronger relationship with OLC than with EPG, reinforcing this observation.

Having established that there are secular, decadal, and ENSO-related variations in the observed EPG and OLC, which have potential implications for circulation patterns, in the second part of this paper, we (i) explore how the joint probability distribution of jet and eddy energy in the Lorenz-1984 model changes depending on selected combinations of EPG and OLC; and (ii) explore whether driving the Lorenz-1984 model with a heuristic ENSO model (Tziperman et al. 1994) that forces either the EPG or the OLC, using coupling parameters derived from the twentieth-century record, can provide insights into the relative sensitivity of the midlatitude circulation to ENSO through either type of hemispheric forcing.

Using simulations of the L84 model forced by combinations of the EPG and OLC that lie in the tails of their joint pdf, we show that the shifts in the pdf of the jet stream and eddy energy are consistent with expectations from observations and GCMs. We then explore the response of the jet and eddy energy to warm and cold ENSO phases in an ENSO-forced version of the L84 model, which is introduced in section $3 \mathrm{~b}$. We investigate two forcing schemes: direct ENSO forcing to (i) the jet stream, through a modification of the EPG; and (ii) the eddies, through a modification of the OLC. The results of the second scheme are found to be more consistent with the types of circulation shifts that are observed between the different ENSO phases. In addition, the shifts in the joint distribution of jet and eddy energy between warm and cold ENSO phases is shown to be in the opposite direction of the shifts in distribution observed between the tails of the joint $\{\mathrm{EPG}, \mathrm{OLC}\}$ pdf that represent secular changes in these variables. The latter indicates that the response of midlatitude circulation to global warming is different from the response to the El Niño teleconnection pattern, consistent with observations from GCM simulations ( $\mathrm{Lu}$ et al. 2008).

\section{Analysis of more than a century of observations}

The large-scale surface boundary conditions for atmospheric variability, described by the NH EPG and the OLC, are influenced, inter alia, by the state and evolution of the interannual and decadal natural variabilities (e.g., ENSO) and, possibly, by long-term anthropogenic forcing. In the following paragraphs, we investigate such relationships and explore the connection between the aforementioned variables and large-scale circulation patterns in the midlatitudes. Details of the datasets and methods used are given in the appendix.

\section{a. Trends}

Figure 1 shows the seasonal surface EPG anomalies in the Northern Hemisphere during the period 1870 2005. Throughout this paper, the winter of any given year is denoted DJF and corresponds to the average value of December of the previous year, and January and February of the given year.

In accordance with the findings of Jain et al. (1999), there exist three periods with warming and cooling trends: 1870-1940 (warming), 1941-75 (cooling), and 1976-2005 (warming). The warming trend appears in all four seasons in the period 1870-1940. In each case, the EPG becomes less negative (decreases in absolute value), which indicates a decrease in the temperature contrast between the equator and the North Pole. The cooling trend in the period $1941-75$ is followed by a warming trend in the period 1976-2005. The decrease in the EPG shown in the historical record is consistent 


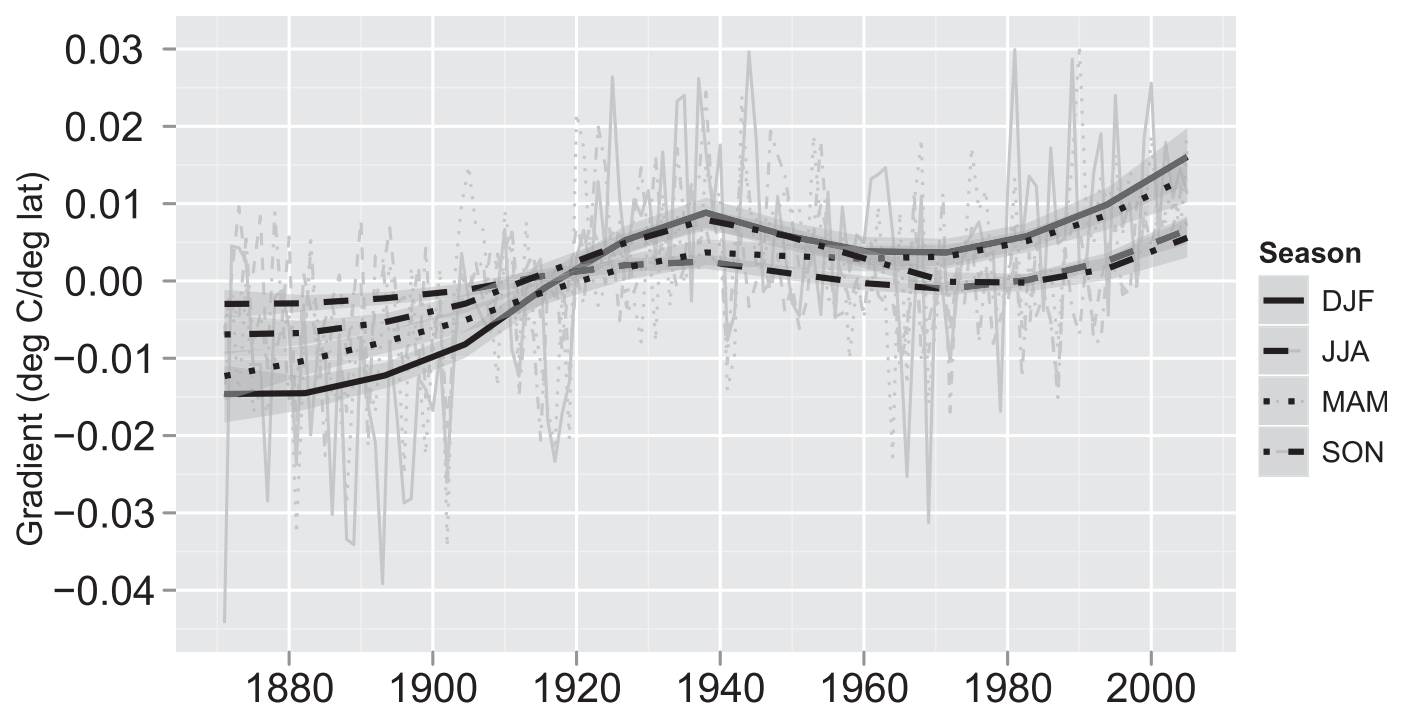

FIG. 1. Northern Hemisphere seasonal EPG anomalies over the twentieth century. Smoothing is done using loess with a span of $13 \mathrm{yr}$. Shaded areas are $95 \%$ confidence intervals.

with the hypothesized poleward amplification of the increase in surface temperature in the Northern Hemisphere due to global warming associated with increased $\mathrm{CO}_{2}$ (Cai and Chu 1998). However, the magnitude of the post-1976 trend of the EPG is not as striking as the one of the global mean temperature anomalies during the same period (e.g., see Hansen et al. 2006); rather, it is comparable to that of the 1870-1940 period. A possible explanation could be that the aforementioned poleward amplification of the increase in surface temperatures in the NH, which accounts for the existing, but small, trend in the EPG series, drives changes in the meridional heat transport, which further reduces the rate of change in EPG. The interplay between the EPG and mean global temperatures has been discussed in Lindzen (1994) and Lindzen and Pan (1994), who argue that paleoclimatic changes were associated with dramatic changes in the EPG, and that the global mean temperature change may be best viewed as a residual arising from a change in the EPG distribution. The observation here that the post1976 steep trend seen in global mean temperatures does not correspond to comparable amplitude changes in the EPG calls for further investigation of the aforementioned interplay and its implications for midlatitude storm tracks.

Figure 2 shows the seasonal OLC anomalies for the zone $40^{\circ}-60^{\circ} \mathrm{N}$ over the twentieth century. The three distinctive periods correspond to a pre-1940 decrease in OLC, a 1941-75 stabilization, and a post-1975 decrease, which is more pronounced in the winter and spring. A decrease in OLC indicates a relative increase in land temperature: OLC is positive in the winter, thus the decrease in the positive value during the winter means that the land temperature is increasing and approaching the ocean temperature. In contrast, OLC is negative in the summer, hence more negative values indicate an increase in land temperature. This is consistent with the general land-driven warming and the delay in the ocean warming in these latitudes (Jones and Briffa 1992; Thomson 1995; Mann and Park 1996).

\section{b. Joint pdf of EPG and OLC and circulation patterns}

Since mutual changes in EPG and OLC can have significant effects on midlatitude atmospheric dynamics, as implied by the regimelike behavior of the L84 model, one needs to examine the changes in their joint probability distribution and the implication for midlatitude circulation. Figure 3 shows the joint probability density of winter OLC $\left(40^{\circ}-60^{\circ} \mathrm{N}\right)$ and EPG after the two variables have been minimum-maximum normalized, that is, after the difference between each variable and its minimum is divided by the range of the variable values. We choose the points at the extremes, which correspond to years 1969 (high EPG and OLC) and 1989 (low EPG and OLC) and are highlighted in the figure, to present an example of how these extremes in the joint distribution of EPG and OLC are manifest in circulation patterns.

Figure 4 shows the difference in (i) mean zonal wind speed at $250 \mathrm{hPa}$, (ii) mean meridional wind speed at $850 \mathrm{hPa}$, (iii) sea level pressure, and (iv) surface air temperature between the winters of 1969 and 1989. In the case of EPG and OLC at their highest extreme (1969), 


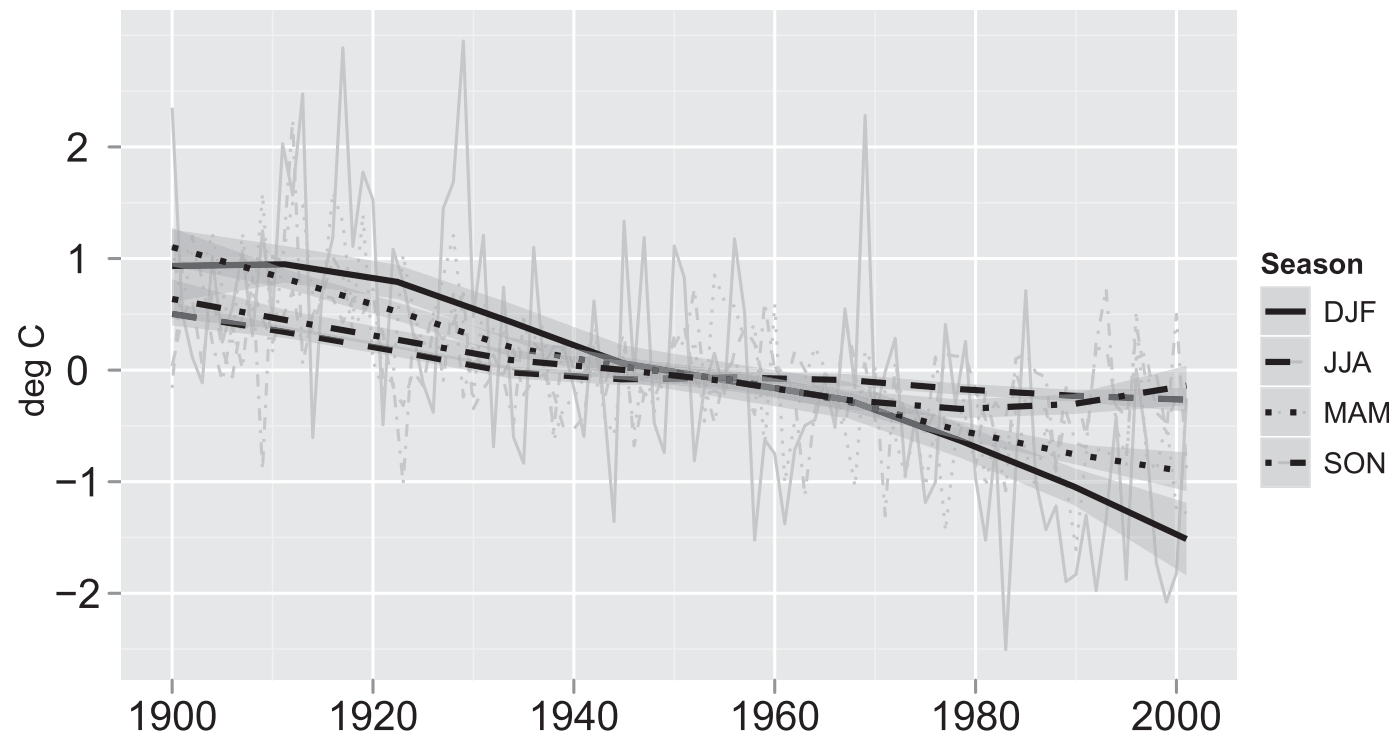

FIG. 2. As in Fig. 1, but for Northern Hemisphere seasonal OLC anomalies $\left(40^{\circ}-60^{\circ} \mathrm{N}\right)$.

the jet stream is located more equatorward in both the Atlantic and Pacific regions (Fig. 4a); at the same time, the high OLC (colder landmasses) could be associated with persistent large-scale systems of high pressure centered over the land areas, leading the large-scale eddies to meander around these high pressure regions. This is more evident over the large landmass of Eurasia: in 1969 the high pressure system, coinciding with low temperatures over the same region (Figs. $4 \mathrm{c}$ and $4 \mathrm{~d}$ ), is associated with poleward eddy transport at the exit region of the Mediterranean flank of the jet and equatorward transport over central Russia (Figs. 4a and 4b). In contrast, in the winter of 1989, when both EPG and OLC are low, the jet stream is positioned at higher latitudes (Fig. 4a). The low OLC is not associated with organized high pressure systems specifically centered over land. A case in point is the high pressure area covering the eastern Pacific and U.S. West Coast region; there, the poleward transport is enhanced in the exit region of the Pacific jet (toward Alaska), meandering around the higher pressure area in the region. This contrast in circulation patterns between cases of high and low pressure $\{$ EPG, OLC $\}$ combinations exists, on average, for all cases in the upper and lower 25th percentiles of the joint $\{$ EPG, OLC $\}$ distribution (not shown here).

\section{c. Interannual to decadal variability of the joint $p d f$ of EPG and $O L C$}

The twentieth-century evolution of the joint distribution of winter EPG and OLC, at decadal time scales, shown in Fig. 5, is in accordance with periods of distinct global temperature shifts. In the beginning of the century, the center of the distribution of EPG and OLC values lies approximately at a combination of longterm mean values for each variable. In the next two decades, the OLC values stay at the same levels but the EPG decreases, that is, there is an apparent warming

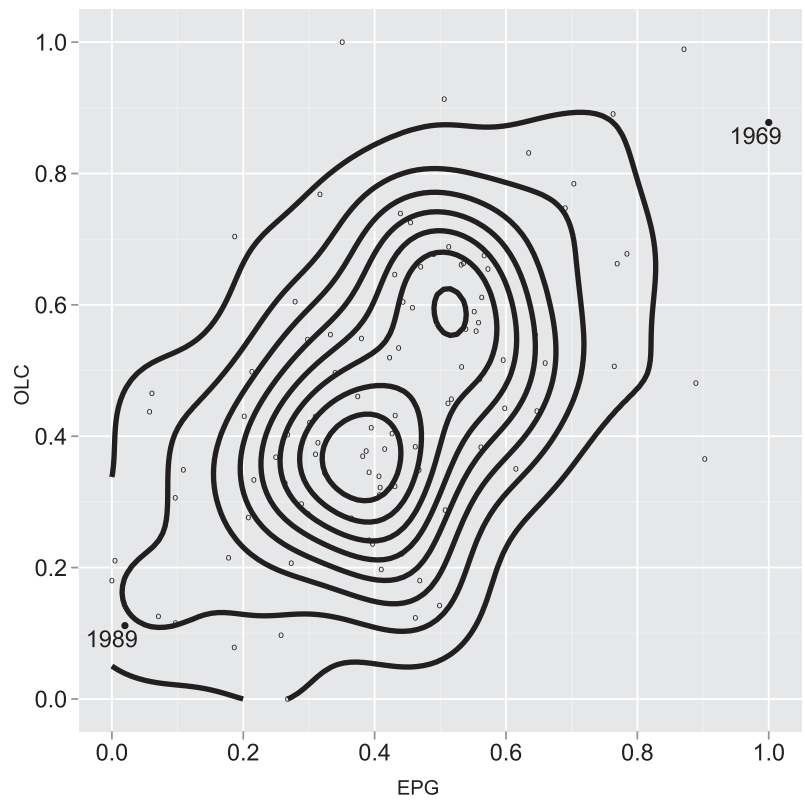

FIG. 3. Joint pdfs of winter EPG and OLC $\left(40^{\circ}-60^{\circ} \mathrm{N}\right)$. The two variables have been min-max normalized, so that 0 denotes the minimum observed absolute value and 1 the maximum. The range of absolute values for winter EPG is [0.7826, 0.8568] and for winter OLC is [11.531, 16.9841]. The marked cases correspond to (a) 1969: high EPG and OLC, and (b) 1989: low EPG and OLC. 

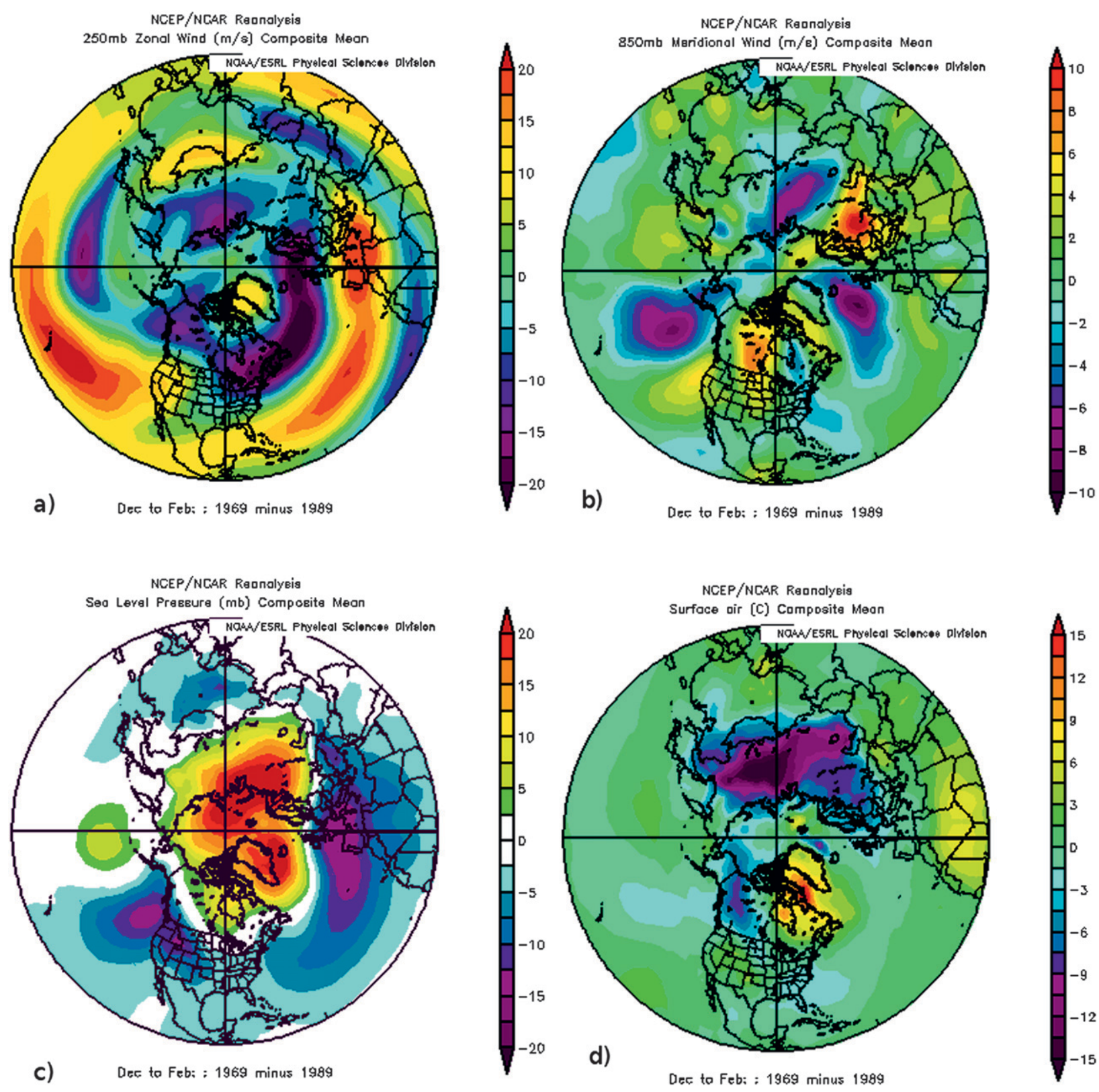

FIG. 4. The difference in (a) mean zonal wind speed at $250 \mathrm{hPa}$, (b) mean meridional wind speed at $850 \mathrm{hPa}$, (c) sea level pressure, and (d) surface air temperature between winter of 1969 and winter of 1989 . The winter of 1969 corresponds to high EPG and OLC, while the winter of 1989 corresponds to low EPG and OLC.

of the higher latitudes with respect to the equator. In the period 1940-60 an apparent bimodality emerges, with one mode lying at the values of the previous two decades and another mode at higher EPG values. This is in accordance with the cooling that was observed in the middle of the twentieth century, which has been linked to increased aerosol emissions due to World War II, increased industrial activities after the war, and a number of volcanic eruptions (Meehl et al. 2004; Wild et al. 2005).
This mode disappears as we enter the 1960's and 1970's. It is in the late twentieth century (1980-2000) that the pronounced warming at higher latitudes (lower EPG) and also the warming of the land regions (low OLC) creates a new mode of combinations of low EPG and low OLC, which, as discussed in the previous section, may be associated with a poleward shift of the jet stream and associated increased precipitation at higher latitudes and drying of lower latitudes. Significance testing of the 

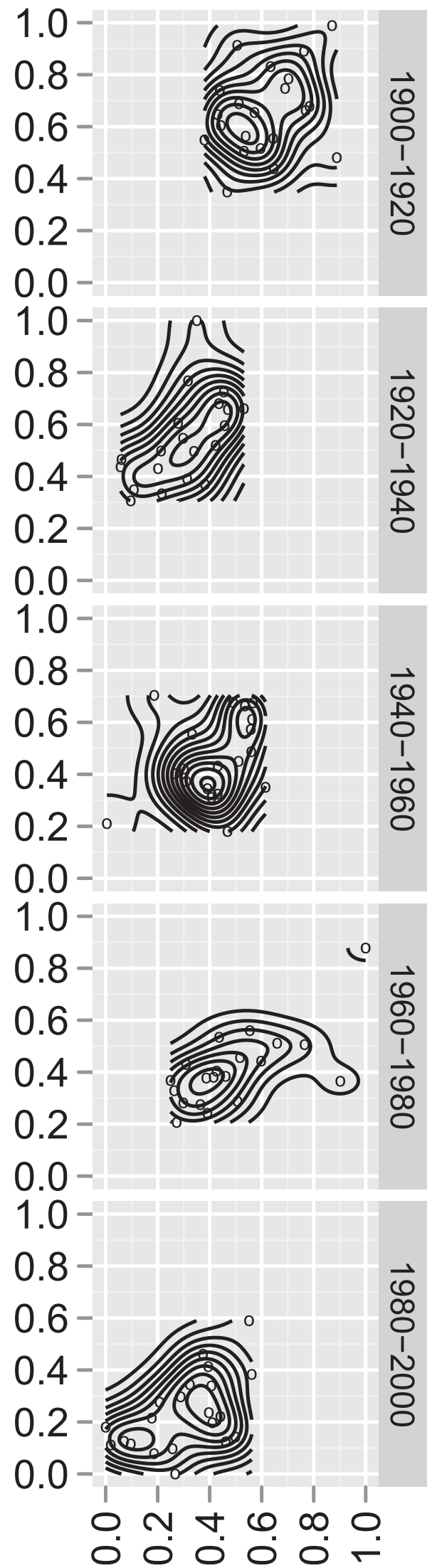

pdf evolution highlights the clear changes between the first half and the second half of the century (see the appendix and Table A2).

\section{d. Empirical connections to ENSO}

In addition to trends that could be attributed to anthropogenic forcing and natural variability associated with solar radiation, changes in energy fluxes, etc., mechanisms of interannual variability, such as ENSO, also have an effect on the meridional and zonal temperature gradients. Figure 6 shows the seasonal cross-correlation function between the detrended north-south temperature gradient at $1000 \mathrm{hPa}$ and the Niño-3 index. In the Northern Hemisphere, the cross-correlation function shown in Fig. 6 peaks in the winter, decreases in the following spring, and disappears during the summer, to be picked up again when the ENSO signals emerge in the fall. This observation is consistent with the seasonality in ENSO and the so-called spring predictability barrier (Zebiak and Cane 1987; Xue et al. 2000; McPhaden 2003).

Figure 7 shows the Hovmöller-type diagram of the cross-correlation function of the OLC and Niño-3 Index for latitudes in the Northern Hemisphere. The thick black lines mark statistical significance $(95 \%)$, and the dashed lines mark the latitudinal zone $40^{\circ}-60^{\circ} \mathrm{N}$. The two series are highly correlated in the tropics, while they are negatively correlated at latitudes of approximately $15^{\circ}$ and $40^{\circ} \mathrm{N}$, and positively correlated at high latitudes (approximately $74^{\circ} \mathrm{N}$ ), throughout the year. Positive correlations "move" from low latitudes in the first half of the year $\left(20^{\circ}-35^{\circ} \mathrm{N}\right)$ to higher latitudes in the second half $\left(40^{\circ}-60^{\circ} \mathrm{N}\right)$. The positive correlation in the zone during the first half of the year is consistent with eddy-driven cooling evidenced in Lu et al. (2008). The negative correlation at $40^{\circ} \mathrm{N}$ peaks in the winter and fall seasons. In the band $40^{\circ}-60^{\circ} \mathrm{N}$, the correlation reverses its sign as the seasons progress and has peak positive values in the summer at $50^{\circ}-60^{\circ} \mathrm{N}$. Higher values of OLC lead to higher eddy intensity and thus greater dynamic instability; the opposite occurs for lower values of OLC. Therefore, Fig. 7 is in accordance with the hypothesis that ENSO warm events reduce eddy energy at the $40^{\circ}-60^{\circ} \mathrm{N}$ latitudinal range and increase it at higher latitudes. In the summer, the positive correlation shifts from higher $\left(70^{\circ}-80^{\circ} \mathrm{N}\right)$ to lower latitudes $\left(40^{\circ}-60^{\circ} \mathrm{N}\right)$ compared to the winter.

FIG. 5. The evolution of the joint pdf of winter EPG and OLC $\left(40^{\circ}-60^{\circ} \mathrm{N}\right)$ over the twentieth century. Axes as in Fig. 3. The pdf exhibits decadal shifts in accordance with distinct global temperature shifts (see text for discussion and appendix for significance testing). 


\section{Cross-correlation Function of NINO3 Index and N-S temperature gradient}

(a) DJF

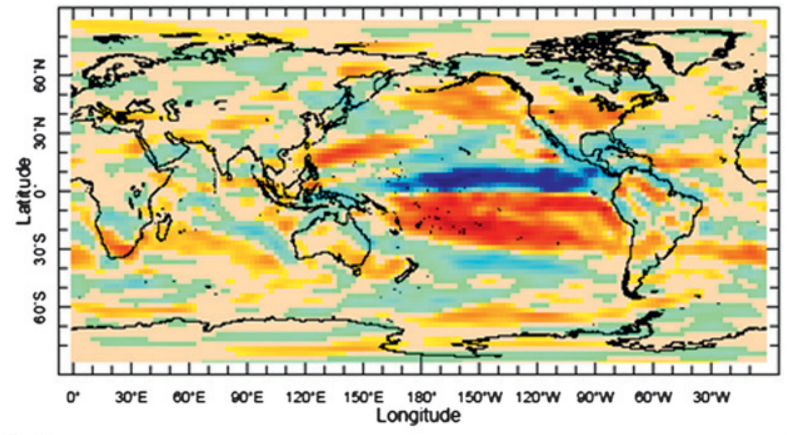

(c) JJA

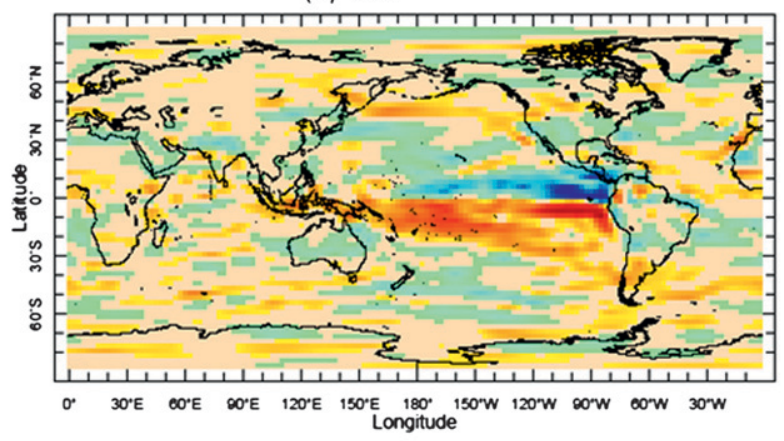

$1000 \mathrm{mb}$ (b) MAM

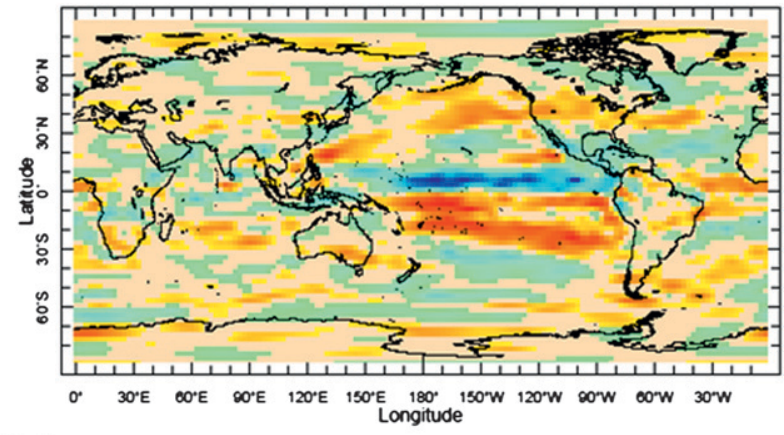

(d) SON

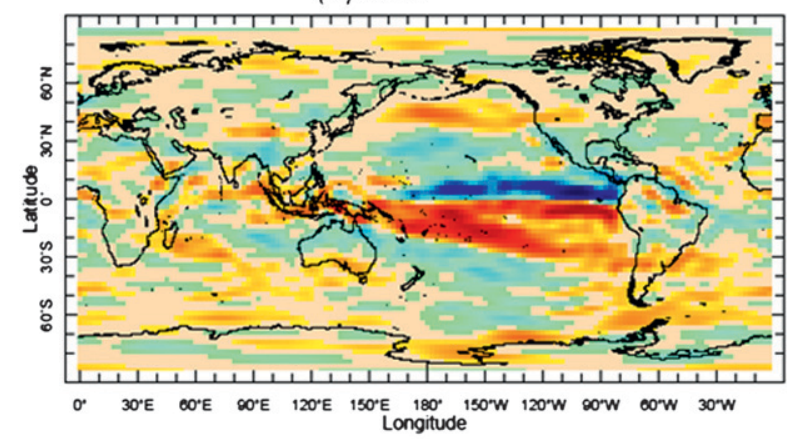

nomono

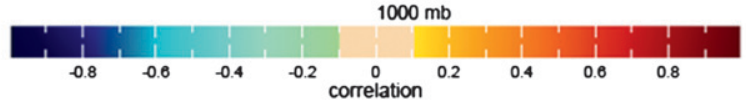

FIG. 6. Seasonal cross-correlation function of the north-south temperature gradient at $1000 \mathrm{hPa}$ and the Niño-3 index. Confidence intervals are $[-0.28,0.28]$.

Figure 8 shows the joint pdf of EPG and OLC with respect to the state of ENSO. The pdf during El Niño (warm) years is found to be significantly different from the one during La Niña (cold) and neutral years (which are similar to each other). EPG variability is constrained around mean values during El Niño years, while during La Niña years there is a greater probability of low EPG values in accordance with a cooling of the tropics. The similarity in the pdfs in La Niña and neutral years is to be expected, given the proximity of the two states in terms of SST anomalies in the equatorial Pacific. (This is corroborated by the significance test presented in Table A3 and described in the appendix.)

The aforementioned changes in the joint pdf of the meridional and zonal temperature gradients with ENSO phase and the connection of the joint pdf to large-scale circulation patterns presented in the section $2 \mathrm{~b}$ motivate a study of the possible connections of midlatitude circulation features with ENSO evolution through the effect of ENSO on the EPG and OLC. This task will be undertaken in section $3 \mathrm{~b}$ of this paper, via an ENSOforced version of the L84 model.

\section{Inferences from low-order models}

\section{a. Effect of changing EPG and OLC on L84}

In this section, we investigate the response of the L84 model to combinations of EPG and OLC. The L84 model can be derived from the two-layer quasigeostrophic model (Holton 2004), via a truncated Fourier series expansion plus a Galerkin projection and a further reduction to a linearized 3D invariant manifold; it preserves the fundamental dynamics of the interaction between the jet stream and the low-level winds, as shown in Van Veen (2003). A detailed description of the model can be found in the appendix; we note here that $X$ is the intensity of a large-scale westerly wind current (i.e., the jet stream), while $Y$ and $Z$ represent the amplitude of the cosine and sine phases, respectively, of a chain of superposed large-scale eddies. The eddies transport heat and moisture poleward at a rate proportional to the square of their amplitude, and they are amplified at the expense of the jet stream. Lorenz (1984) considers $Y$ and $Z$ to describe large-scale Rossby waves; however, the model lacks a mechanism for wave 


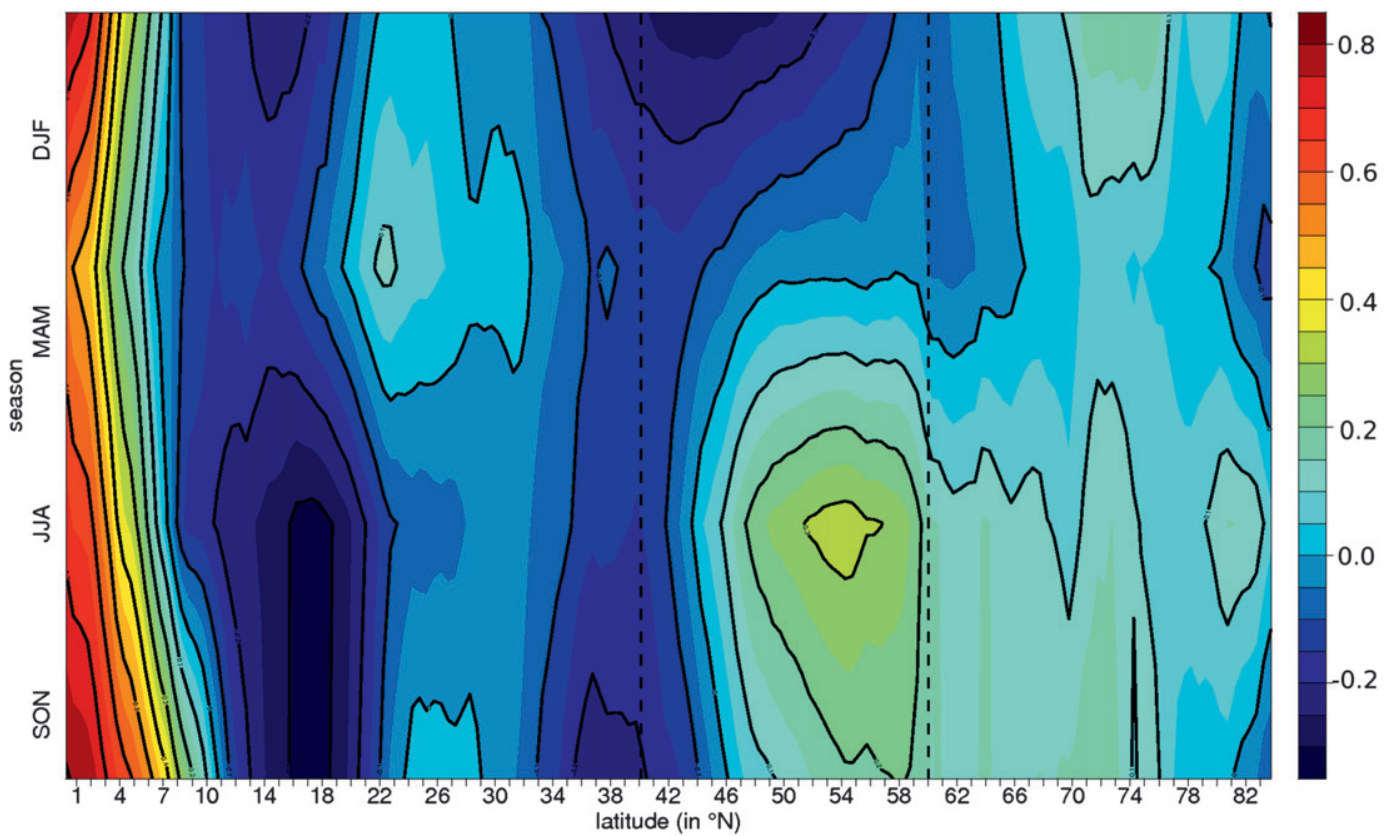

FIG. 7. A Hovmöller-type diagram of the cross-correlation function of the OLC and Niño-3 index in the Northern Hemisphere. The thick black lines mark statistical significance $(95 \%)$, and the dashed lines mark the latitudinal zone $40^{\circ}-60^{\circ} \mathrm{N}$. The plot reflects the observed and modeled changes in eddy-driven circulation during ENSO events (see text for discussion).

propagation. Therefore, distinguishing between stationary and transient eddies is not possible in this model. The terms $F$ and $G$ describe the symmetric and asymmetric thermal forcing, respectively, which Lorenz (1984) identifies with the equator-to-pole and ocean-land temperature gradients. Here, we normalize the observed EPG and OLC values to correspond to the idealized forcing parameters in the L84 model (see the appendix).

We examine how the joint pdf of jet stream energy (proportional to $X^{2}$ ) and eddy energy (proportional to $Y^{2}+Z^{2}$ ) in the model responds to selected EPG and OLC conditions. Given the shift from higher to lower values of EPG and OLC in the record, shown in Fig. 5, it is of interest to examine the response of the model to two cases in the tails of the joint pdf of EPG and OLC. We perform the experiments presented in Table 1 for forcing that corresponds to the following cases: (i) 1969 , which reflects a high EPG and OLC; and (ii) 1989, which had low EPG and OLC. The change across these two years is loosely taken as a potential shift toward global warming conditions, in accordance with the trends in EPG, OLC, and their joint density presented in section 2 .

As per Jain (1998), we note that the phase space of the L84 model simulations is quite different for spring and fall, when a seasonally varying forcing of EPG and OLC is considered. Also, the tendency of EPG and OLC [e.g., EPG decreasing (increasing) in the spring (fall)], and hence of the states of the L84 variables, matters for the subsequent seasons. Consequently, we run the model in its seasonally varying form [Eqs. (A9)] and extract the winter values of $X, Y$, and $Z$ for subsequent analyses.

Figure 9 shows the joint pdf of winter eddy energy and jet stream energy for the simulations under perpetual (i) 1969 or (ii) 1989 conditions; Fig. 9c shows the difference in the joint pdf between 1989 and 1969 winters. Figure $9 d$ shows the univariate pdf of the jet stream energy.

In the case of 1969, when the EPG and OLC are both at high values, the eddy energy varies along the $y$ axis and has higher variance and skewness, with the main mode at a higher level compared to the 1989 case. In the case of 1989, when both EPG and OLC take low values, both the probabilities of strong eddies and of strong jet stream are reduced, and a moderate mean zonal flow is preferred. This is also indicated by the pdf of the jet energy in Fig. 9d, where the tails are lighter in 1989 compared to 1969. The weaker eddy energy in 1989 is consistent with the expectation of weaker stationary eddies in a warmer climate (Joseph et al. 2004). In the L84 results, this weakening of the eddies favors a more zonally symmetric flow (or vice versa), shown in the shift in the joint pdf from the tails to a mode centered at moderate values for both the eddies and the jet. This result is also consistent with the findings of Joseph et al. 

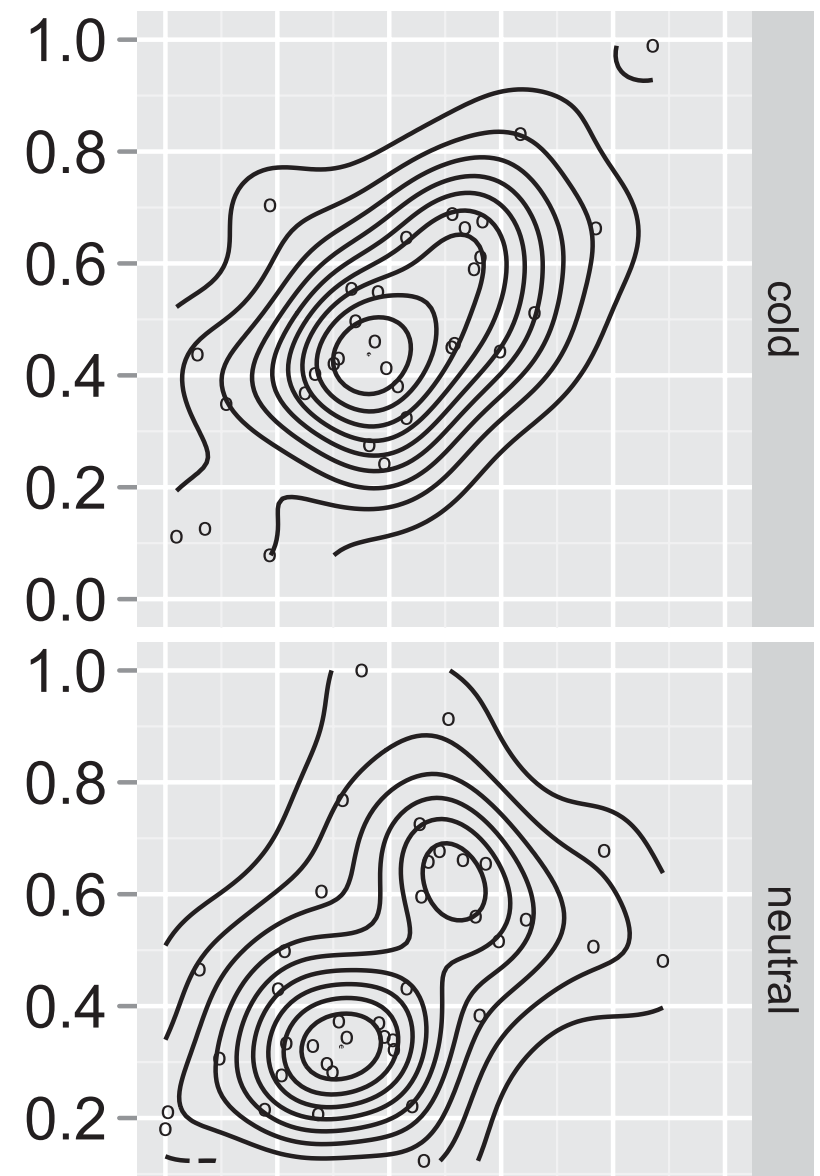

$0.0-$
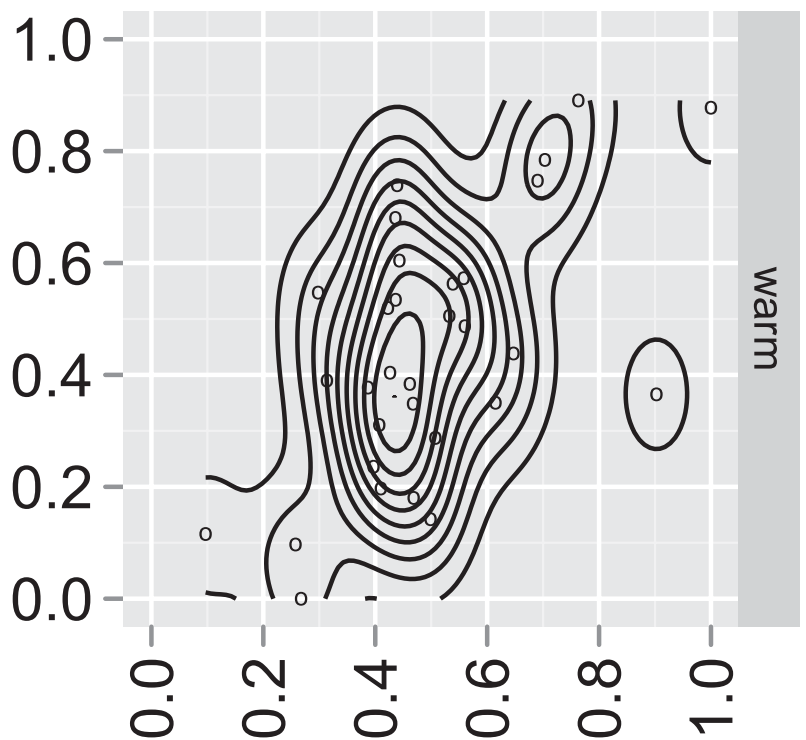

FIG. 8. The joint pdf of winter EPG and OLC with respect to the state of ENSO. The pdf during El Niño years is significantly different from the one during La Niña (cold) and neutral years (also see Table A3). Axes as in Fig. 3.
(2004), who show that the reduction in the amplitude of the stationary waves in a climate change scenario is primarily caused by the change in the zonal mean basic state. In a model that considers the EPG as the main external driver of the jet stream, this result may seem counterintuitive at first, since a decrease in EPG should act toward further weakening the jet. However, given the nonlinearity of the model, it is not entirely unexpected. The effect of the EPG on the jet is a linear amplification, while a weakening of the eddies interacts with the jet stream in a nonlinear fashion [see Eq. (A6)]. By comparing the relative magnitude of the rhs terms, it can be shown that the nonlinear terms in the tendency equation (A6) dominate over the linear terms and can explain the shift in the joint pdf in Fig. 9c. In fact, the result is in qualitative consistency with GCM projections, which show a strengthening of the upper-level zonal wind (Lorenz and DeWeaver 2007).

\section{b. The ENSO-forced L84 model}

It has been suggested by Lu et al. (2008) that the response of midlatitude circulation to global warming is in the opposite direction of the response to the El Niño teleconnection pattern. The sensitivity of the jet and storm tracks to the distribution of SST warming (e.g., see Inatsu et al. 2003; Brayshaw et al. 2008; Lu et al. 2010) could be considered to explain the distinct responses. Here, by construction of the EPG variable (see the appendix), the broader the latitudinal belt of warming (as in the global warming case), the smaller its effect on the value of EPG. Conversely, a narrow warming of the tropics during El Niño events would increase the EPG more. Indeed, as shown in Fig. 8c, in El Niño years the EPG is constrained in the middle portion of the $x$ axis and has higher values compared to the La Niña years.

The relationship between tropical SSTs, and particularly ENSO-induced SST anomalies, and midlatitude circulation has been investigated in various papers (Ropelewski and Halpert 1987; Kumar and Hoerling 1995; Kumar et al. 1994). Interannual differences in the spectral distributions and organization of extratropical eddies in response to ENSO events have been explored (Mechoso et al. 1987; Hoerling and Ting 1994). Various teleconnection patterns have been suggested for the influence of ENSO on the midlatitudes (e.g., Wang 2004; Palmer and Mansfield 1986a,b). Much of the related literature is discussed in Hoerling et al. (1995), Müller and Roeckner (2008), and Strong and Davis (2008). Several ways by which ENSO dynamics may receive feedbacks from midlatitudes have also been proposed $(\mathrm{Gu}$ and Philander 1997; Kleeman et al. 1999; Barnett et al. 1999). In this paper we consider only the forcing of the highfrequency midlatitude atmospheric circulation dynamics 
TABLE 1. Experiments performed to explore the response of jet stream and eddy energy to combinations of EPG and OLC $\left(40^{\circ}-60^{\circ} \mathrm{N}\right)$. Subscripts $w$ and $s$ denote winter and summer, respectively. The winter of 1969 exhibited high EPG and OLC, and the winter of 1989 exhibited low EPG and OLC (see Fig. 3).

\begin{tabular}{|c|c|c|c|c|c|c|c|c|}
\hline Conditions & $F_{w}(\mathrm{EPG})$ & $G_{w}(\mathrm{OLC})$ & $F_{s}(\mathrm{EPG})$ & $G_{s}(\mathrm{OLC})$ & $F_{0}$ & $F_{1}$ & $G_{0}$ & $G_{1}$ \\
\hline Typical (mean) & $8(-0.81)$ & 1 (14.04) & $6(-0.35)$ & $-1(-3.49)$ & 7 & 1.5625 & 0 & 1.5625 \\
\hline $1968 / 69$ & $8.3(-0.84)$ & $1.16(16.32)$ & $6.3(-0.37)$ & $-0.98(-3.43)$ & 7.3 & 1.5625 & 0.09 & 1.675 \\
\hline $1988 / 89$ & $7.7(-0.78)$ & $0.86(12.14)$ & $6(-0.35)$ & $-1.04(-3.65)$ & 6.85 & 1.3281 & -0.088 & 1.488 \\
\hline
\end{tabular}

by the slowly varying ENSO state as manifest in the EPG and/or the OLC.

In this section, following an approach similar to Roebber et al. (1997), we examine two different ways of dynamically forcing the L84 model with a heuristic model of ENSO (Tziperman et al. 1994), motivated by the observational analysis in section 2: (i) delayed forcing of the midlatitude mean zonal wind $X$ by ENSO through the EPG and (ii) forcing of the midlatitude eddies $Y, Z$ by ENSO though the OLC. Roebber et al. (1997) showed that simulations with prescribed SSTs differ significantly from L84 model simulations with dynamic forcing by an ENSO model. Here, we discuss the effect of each of the aforementioned types of forcing on the statistics of the atmospheric components of the L84 model. Unlike past work, we directly estimate the forcing parameters in the model from historical data on the EPG, the OLC, and the Niño-3 index. Seasonal variations in the EPG and OLC and in the forcing of these variables by ENSO are considered in order to get an appropriate representation of the potential asymmetries in forcing over the year, as indicated by the data. A detailed description of the model is given in the appendix.

Figure 10 shows the effect of ENSO phases on the joint pdf of winter jet stream and eddy energy for the different forcing approaches. The left panels show the composite joint pdf for El Niño winters, while the right panels show the difference between El Niño and La Niña winters.

When ENSO forces the jet stream equation, via its forcing of the EPG, the change in the joint pdf between El Niño and La Niña winters is not pronounced (Fig. 10b), even though it seems consistent with the general strengthening of the jet stream during El Niño winters (Seager et al. 2003). The heavier tails that correspond to increased potential for higher jet energy in El Niño versus La Niña winters is also seen in the case of ENSO forcing on the eddy equation (Fig. 10d). This forcing approach results in greater organization of the joint pdf of jet and eddy energy (Fig. 10c). This observation suggests that the information channel connecting midlatitude storm-track predictability and ENSO may relate more to the baseline changes induced in OLC than EPG. This is consistent with the notion that the ENSO effects in midlatitudes are realized through Rossby wave propagation (Seager et al. 2003). This observation is also supported by the agreement of the correlations in Fig. 7 with observed changes in eddy activity in response to ENSO events, as discussed in section 2. The most notable result is, however, obtained by the comparison of Figs. 9c and 10d: The $1989-1969$ pattern (Fig. 9c), which acts as our paradigm of a global warming trend, is in its main mode opposite of the pattern in Fig. 10d. In the 1989 - 1969 case, the probability mass is centered with
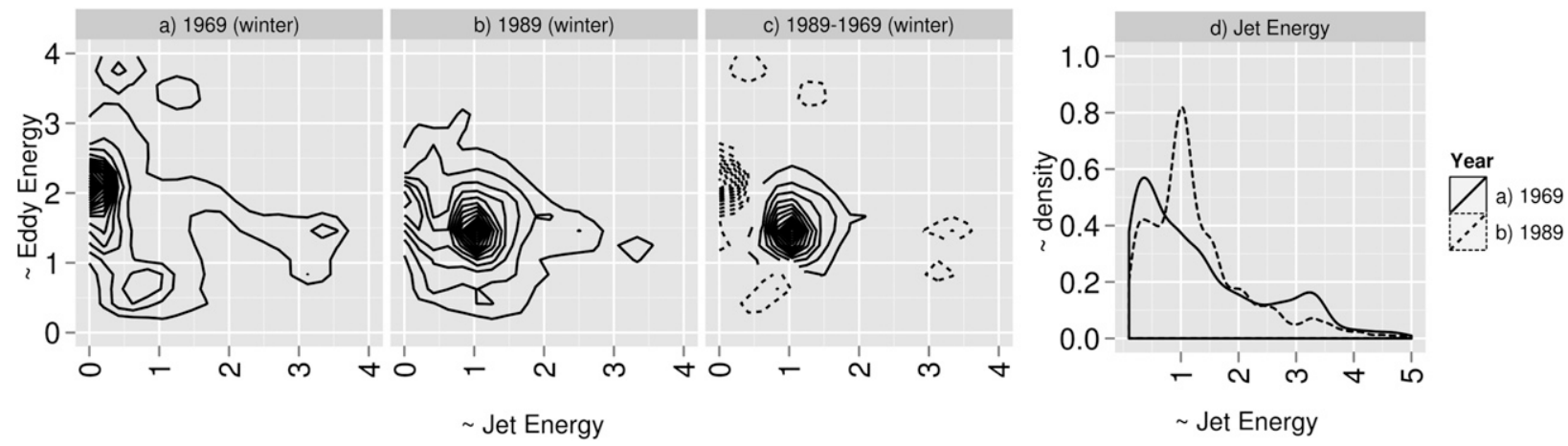

FIG. 9. The joint pdf of winter eddy energy and jet stream energy from the simulations of the L84 model. (a) 1969: the system exhibits main modes at enhanced eddy energy and a weaker mode at high jet stream energy. (b) 1989: the probability is shifted and concentrates in moderate jet and eddy values. (c) The difference between the 1989 and 1969 pdfs. In 1989 both the probability of strong eddies and of strong jet stream is weakened and a moderate mean zonal flow is preferred. (d) The univariate pdf of jet energy shows lighter tails in 1989. Contours in the range $[-1,1]$ at a 0.05 interval. Dashed lines denote negative values. 


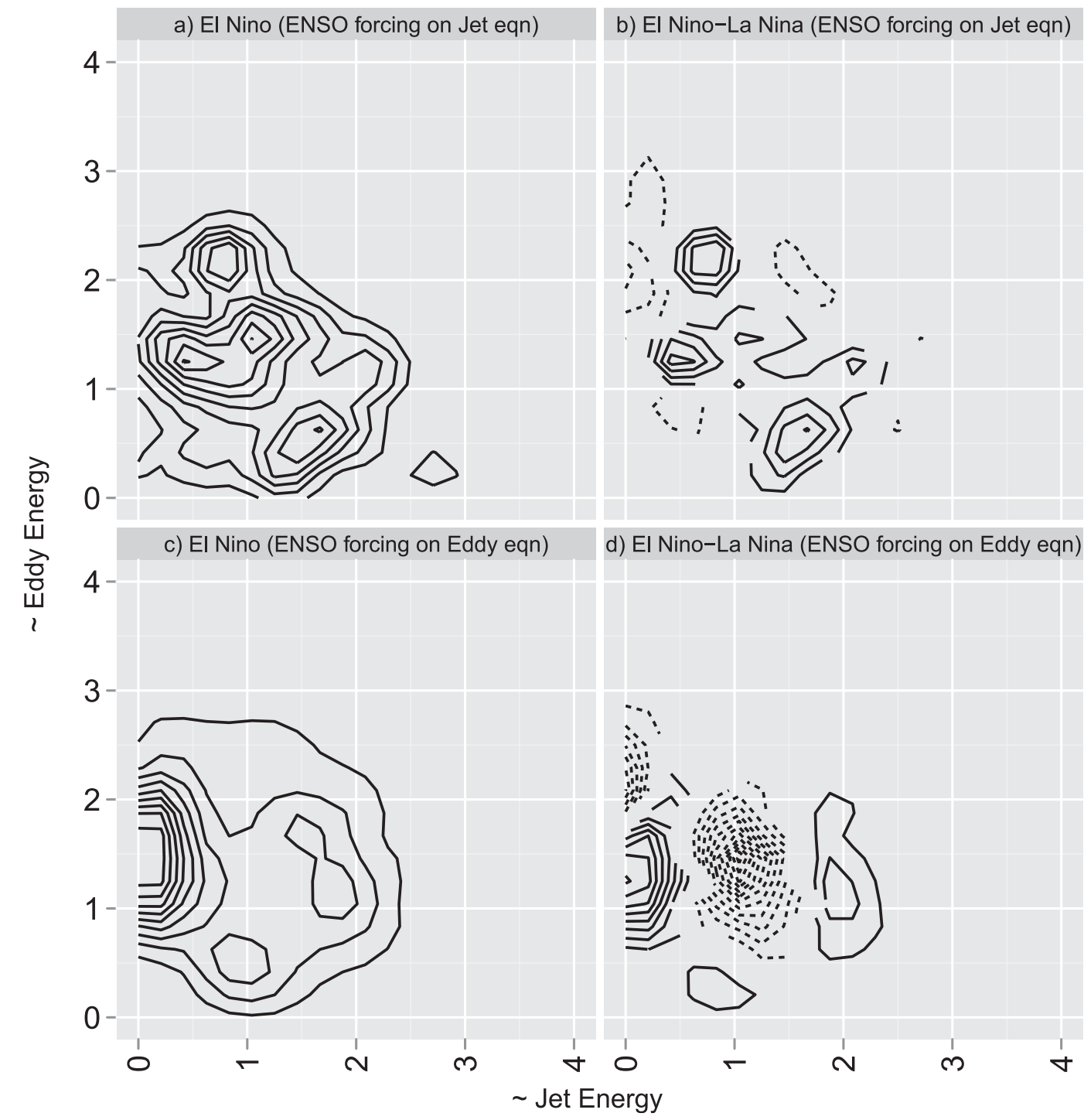

FIG. 10. The joint density function of eddy energy and jet stream energy for El Niño winters and the difference with La Niña winters in the ENSO-forced L84 model. (a),(b) ENSO forcing to the jet stream equation. (c),(d) ENSO forcing to the eddy equations. Contours in the range $[-1,1]$ at a 0.05 interval. Dashed lines denote negative values.

respect to jet stream energy, while in the El Niño-La Niña case the probability mass is shifted to the tails. This is qualitatively consistent with the results of comprehensive GCMs, as shown in Lu et al. (2008), who noted that in the GCMs they examined, "the extratropical atmospheric responses to global warming occur in a somewhat opposite fashion to the El Niño teleconnection pattern" (p. 5836).

\section{Summary and discussion}

Climate models and analyses have become increasingly sophisticated over the last few decades. Consequently, a diagnostic and low-order model analysis focused on assessing whether a pair of large-scale variables provides an interesting conceptual bridge between slow and fast dynamics in a statistical context may seem odd. E. Lorenz and B. Saltzman (1995, personal communication) suggested the idea of thinking about how changes in planetary orbital parameters, or anthropogenic changes in radiative forcing, or ENSO phases may change the EPG and OLC, and how these changes would in turn manifest as changes in specific attributes of hemispheric circulation. While Jain et al. (1999) made an initial investigation into the trends in the mean values and the seasonality of these variables, and the implications of such changes, little subsequent research on these indicators has followed. Consequently, given updated 
climate data, a first objective of the current paper was to update specific aspects of that work. We focused on the joint probability density function of the EPG and the OLC, and showed how it changes over the twentieth century and in response to ENSO phases. Combinations of the EPG and OLC at the tails of the distribution were shown to relate to variability in large-scale circulation patterns in the Northern Hemisphere. In addition, the joint pdf of the EPG and the OLC during El Niño events was found to be distinct from the one during La Niña and neutral states. The discernible differences between the joint pdf and their relation to circulation patterns are consistent with the generally expected outcomes given GCM and data analyses.

We were then curious whether the changes in the EPG and the OLC induced by anthropogenic warmingthat is, a decrease in both variables-would lead to changes in the circulation attributes in a simple dynamical model that parameterizes only a few aspects of the midlatitude circulation, namely, the Lorenz (1984) model. While the L84 model and its coupling with ENSO dynamics have been well studied (see the appendix for details), the present study is the first one to fit the L84 forcing parameters to the historical data. Thus, we attempted to explore a resulting solution space of the L84 model that is consistent in some sense with the twentiethcentury data.

First, we examined the joint distributions of the jet stream and eddy energy under EPG and OLC conditions, corresponding to opposite tails of the joint $\{\mathrm{EPG}$, OLC $\}$ pdf: (i) a case corresponding to conditions mostly observed in the beginning of the twentieth century; and (ii) a case corresponding to conditions mostly observed toward the end of the twentieth century, which acted as a global warming paradigm. The differences in the joint distributions are consistent with a weakening of the eddies and an enhanced upper-level mean zonal flow as a response of midlatitude circulation to global warming, which is suggested by more complex GCMs (e.g., Joseph et al. 2004; O'Gorman and Schneider 2008; HernándezDeckers and von Storch 2011), despite the fact that the low-order model does not consider moist dynamics. With regard to the response of jet stream dynamics to global warming, it has been shown that more comprehensive, yet dry, models (e.g., Lorenz and DeWeaver 2007; Butler et al. 2011) give results that are in agreement with the projections of fully developed GCMs.

Second, we explored the response of midlatitude circulation to different ENSO phases, which behooved the use of a more complex version of the L84 model, in which a heuristic ENSO model forces midlatitude circulation though a dynamic forcing of the EPG and OLC. We noted a greater organization of the joint pdf of jet stream and eddy energy when ENSO forces the eddies directly. In El Niño years, the probability mass shifts from intermediate values to the tails of the jet energy. By contrast, for the EPG-OLC combinations loosely associated with warmer versus colder climate, the probability mass moves toward intermediate jet energy values. The different response of the model to global warming versus ENSO is consistent with the results of more comprehensive GCMs, even though this simple low-order model lacks moist dynamics, vertical structure, etc.

While the L84 model informs us as to a rather limited aspect of the hemispheric atmospheric circulation dynamics, the conclusion is that changes in the EPG and the OLC induced by ENSO or anthropogenic warming, or other factors, can be qualitatively mapped into changes in circulation parameters that are informative of the partitioning of the midlatitude jet stream and eddy energy. The partitioning of jet and eddy energy is particularly relevant in the entrance and exit regions of the jet (see Holton (2004)). In those regions, eddy propagation has been linked to the variability of the jet latitude (Kidston et al. 2010), and the persistence of latitudinal jet shifts has been associated with the jet-eddy interaction (Gerber and Vallis 2007; Barnes et al. 2010). Hence, even though the simple L84 model is not capable of representing latitudinal shifts of the jet stream, exploring the partitioning of the energy between the jet stream and the eddies is implicitly relevant to the questions surrounding the latitude of the jet stream and the storm tracks, and their potential poleward shifts in future GCM projections (Yin 2005). In addition, such changes in the partitioning of the jet and eddy energy are proportional to precipitation potential. Hence, independent of potential changes in moisture dynamics, one can assess how the aforementioned aspects of circulation that impact precipitation may change.

The insights developed here lend confidence that further investigations of EPG/OLC changes may be a useful way to build intuition as to potential changes in the seasonality and probability distribution of midlatitude circulation. This line of inquiry is based on the notion that slow changes in large-scale parameters, which can be brought about by low-frequency natural variability or anthropogenic climate change, can have significant impacts on the persistence of the different states of synoptic circulation. In the context of the present study, the "slow" parameters are EPG and OLC, the "fast" variables are the jet stream and eddy energy, and the persistence of the states of synoptic circulation is approached via the probability density function, since each mode of the pdf corresponds to a different circulation regime.

Investigations motivated by this line of thought can utilize the hierarchy of models-from simple low-order 
models, such as the ones used in this study, to comprehensive GCMs - and can have interesting applications. For example, these studies can identify causal relationships between intermediate variables, such as the EPG and OLC, and target variables, such as precipitation intermittence and intensity. These can then be used to build multimodel combinations of GCM output by focusing on reducing the model biases on the trends and the variability of the EPG and OLC. If successful, such a bias correction could offer hope for large-scale improvement of resolved-scale precipitation output, instead of doing such bias corrections for each region of interest, as is done in many applications today.

Acknowledgments. The authors thank Dr. Paolo Di Giamberardino (La Sapienza-University of Rome) for his valuable help in computer programming. We acknowledge the IRI Data Library for providing data. CK is supported by the NASA Earth and Space Science Fellowship NNX09AN91H and the Alexander S. Onassis Public Benefit Foundation Scholarship Program. The line of inquiry reported here originally emerged through discussions between U. Lall, B. Saltzman, and E. Lorenz. The contributions of Shaleen Jain to the initial development of these ideas are acknowledged. Many thanks are due to J. F. Booth and the three anonymous reviewers for their constructive comments.

\section{APPENDIX}

\section{Data and Methods}

\section{a. Data}

The data used for the EPG and OLC calculations are monthly Northern Hemisphere data from the varianceadjusted version of the Hadley Centre Climatic Research Unit temperature anomaly (HadCRUT; temperatures span $2.5^{\circ}-72.5^{\circ} \mathrm{N}$ and are averaged over all longitudes); see Brohan et al. (2006). Figures 4 and 6 use National Centers for Environmental Prediction-National Center for Atmospheric Research (NCEP-NCAR) reanalysis data (Kalnay et al. 1996), spanning the period 19492010. The Niño-3 index is from Kaplan et al. (1998) and Reynolds et al. (2002). Maps are provided by the International Research Institute for Climate and Society (IRI) Data Library and the National Oceanic and Atmospheric Administration (NOAA) Earth System Research Laboratory (ESRL)'s Physical Sciences Division in Boulder, Colorado, from their website (http://www. esrl.noaa.gov/psd/).

Smoothing of the EPG and OLC time series is done using loess with a span of one-tenth of the length of the record in each case.

\section{b. Equator-to-pole temperature gradient (EPG)}

The gradient is calculated according to Jain et al. (1999).

Monthly temperature is represented by $\bar{T}_{i t}$, defined as

$$
\bar{T}_{i t}=\sum_{j=1}^{n} \frac{T_{i j t}}{n},
$$

where $\overline{(\cdot)}$ represents the zonal average; $j=1, \ldots, n$ is the longitude index; $i=1, \ldots, m$ is the latitudinal zone index for $m$ latitude zones; and $t=1, \ldots, 12$ is the calendarmonth index. The gradient results from weighted least squares regression, with weights given by

$$
w_{i}=\frac{\cos \left(\phi_{i}\right)}{\sum_{i=1}^{m} \cos \left(\phi_{i}\right)}
$$

where $\phi_{i}$ denotes the latitude.

In matrix notation, if $\mathbf{y}$ is the temperature per latitude, $\mathbf{X}$ is the vector of latitudes, and $\mathbf{W}$ is the vector of weights, given by Eq. (A2), then weighted least squares regression is given by Eq. (A3):

$$
\mathbf{X}^{\mathrm{T}} \mathbf{W} \mathbf{y}=\mathbf{X}^{\mathrm{T}} \mathbf{W} \mathbf{X} .
$$

The average seasonal EPG is computed as the average of the corresponding three monthly EPG values:

$$
\mathrm{EPG}_{s}=\frac{1}{3} \sum_{t=1}^{3} \mathrm{EPG}_{t}
$$

where the subscript $s$ denotes the season. The EPG is expressed in degrees Celsius per latitude.

\section{c. Ocean-land temperature contrast (OLC)}

The monthly OLC is obtained by averaging ocean and land temperatures over all longitudes, as in Eq. (A1), taking their weighted average over each latitudinal zone and, finally, subtracting the land values from the respective ocean values. For each latitudinal zone $i$, OLC is given by

$$
\mathrm{OLC}_{i t}=\bar{T}_{i t}^{\mathrm{ocean}}-\bar{T}_{i t}^{\mathrm{land}}
$$

The average seasonal OLC is computed as the average of the corresponding three monthly OLC values, as in Eq. (A4). The OLC is expressed in degrees Celsius.

\section{d. The L84 model and parameter estimation}

The L84 model addresses certain characteristics of extratropical circulation, namely, a mean zonal westward 
wind caused by the equator-to-pole thermal gradient and by the earth's rotation and the superposed eddies, which transport mass, energy, and momentum, as driven by the EPG and the OLC.

The Lorenz equations [Eqs. (A6)-(A8)] can be derived from the two-layer quasigeostrophic model (Holton 2004) via a truncated Fourier series expansion plus a Galerkin projection and a further reduction to a linearized 3D invariant manifold (Van Veen 2003), and are as follows:

$$
\begin{aligned}
& \dot{X}=-Y^{2}-Z^{2}-\alpha X+\alpha F, \\
& \dot{Y}=X Y-b X Z-Y+G, \quad \text { and } \\
& \dot{Z}=b X Y+X Z-Z,
\end{aligned}
$$

where

$$
\begin{aligned}
F & =F_{0}+F_{1} \cos \left(\omega_{\alpha} t\right) \text { and } \\
G & =G_{0}+G_{1} \cos \left(\omega_{\alpha} t\right) .
\end{aligned}
$$

Here, $X$ denotes the intensity of a large-scale westerly wind current (i.e., the jet stream) and also the geostrophically equivalent large-scale poleward temperature gradient that is assumed to be in equilibrium with it. The terms $Y$ and $Z$ represent the amplitude of the cosine and sine phases, respectively, of a chain of superposed eddies, which transport heat poleward at a rate proportional to the square of their amplitude and transport no angular momentum. The nonlinear terms $X Y$ and $X Z$ represent the amplification of the eddies through interaction with the jet stream, at the expense of the latter, as indicated by the terms $-Y^{2}-Z^{2}$ in Eq. (A6). The terms $-b X Z$ and $b X Y$ represent the displacement of the eddies by the jet stream; for a coefficient $b$ greater than unity, the displacement occurs more rapidly than the amplification. The linear terms represent mechanical and thermal damping; for a coefficient $\alpha$ less than unity, the westerly current damps less rapidly than the eddies. The terms $\alpha F$ and $G$ [Eqs. (A9)] represent symmetric and asymmetric thermal forcing, respectively, and vary with the annual cycle of solar radiation, changes in regional albedo, and alterations in energy exchanges. In the absence of coupling between the mean zonal wind and the superposed eddies, the former should approach a damped EPG (represented by $F$ ) and the latter should approach OLC (represented by $G$ ).

The $F$ and $G$ parameters are computed as follows: We assume that the typical values provided by Lorenz (1984) of $F_{w}=8, G_{w}=1$ and $F_{s}=6, G_{s}=-1$ for winter and summer, respectively, correspond to the mean values of EPG and OLC for DJF and JJA. For OLC, we consider the mean value of the latitudinal zone $40^{\circ}-60^{\circ} \mathrm{N}$. We set Eqs. (A9) equal to the corresponding values for winter and summer for each year, and solve the system of equations to get the input values for $F_{0}, F_{1}, G_{0}$, and $G_{1}$ for the model, as shown in Table 1 . The values proposed by Lorenz (1984) of $\alpha=0.25$ and $b=4.0$ were used. All simulations were sampled at a 5-day time step.

We note that the model has been extensively studied (Lorenz 1990; Broer et al. 2002; Freire et al. 2008; among others), and its coupling to models of the thermohaline circulation and ENSO, through their modulation of the EPG and OLC, has also been pursued. Roebber et al. (1997) compare the results of the L84 model forced by prescribed SSTs to those of a coupled atmosphereocean model, which comprises the L84 model and the heuristic model of ENSO discussed by Tziperman et al. (1994). Based on the substantial differences in the results between the forced and the coupled model, the authors argue that caution should be taken when interpreting the results of forced higher-order models. Earlier, Roebber (1995) also proposed a coupling of the L84 model to a Stommel-like ocean box model. Van Veen et al. (2001) follow up on the analysis by Roebber (1995) and investigate in detail the dynamics of the model, showing that whether the ocean is passive or active depends on small changes in the coupling parameters. The work by Van Veen et al. (2001) illustrates how low-order models can be used to assess the feedback between the two subsystems, and, thus, gain a better understanding of the underlying physics of climate models. In a similar context, Jain (1998) used a range of low-order climate models, including the L84, for tropical-extratropical interactions to develop insights into the nature of midlatitudinal circulation and the associated global teleconnections via investigation of the quasi-periodicity, intransitivity, and chaotic dynamics exhibited in the models. The study suggests that inferences drawn by such simple models can "serve as guidelines for a choice of key parameters in complex models, development of suitable parameterization for key processes and arriving at reasonable hypotheses to be tested on sophisticated models" (p. 167). In a recent paper, Roebber (2009) presents an application of the L84 model to the study of irregular cyclogenesis and blocking over the North Atlantic, and illustrates how the intuition offered by the low-order model provides a basis for organizing observational analyses.

All of these studies use idealized values of the forcing terms (the EPG and the OLC), following the suggestions in the original paper by Lorenz (1984). Such analyses of low-order models have been impressive in their ability to offer interpretations of the underlying behavior without losing quantitative rigor (Lorenz 1982; Simonnet 
et al. 2009), including educational interpretations of how anthropogenic warming may change the frequency of circulation modes (Palmer 2005; Palmer et al. 2005).

\section{e. The coupled L84-ENSO model and parameter estimation}

The L84 equations are coupled with a single-equation model of ENSO, following the work of Roebber et al. (1997). The ENSO model [Eqs. (A10) and (A11); Tziperman et al. (1994) after Munnich et al. (1991) after Cane and Zebiak (1985)] includes a Kelvin wave, a Rossby wave mode, a dynamic link from mid-Pacific wind stress anomalies to the aforementioned wave modes, and a phenomenological seasonal forcing term, which represents the effects of seasonally varying features of the equatorial Pacific Ocean and atmosphere. The model allows the system to enter into nonlinear resonance with the seasonal cycle at several periods of the oscillators and, thus, the authors argue that nonlinearity could explain the irregular occurrence and partial locking to the regular seasonal cycle of El Niño. The thermocline depth anomaly in the eastern equatorial pacific is denoted by $h, t$ is time, $L$ is the basin width, and $\omega_{\alpha}$ is the annual frequency of the idealized seasonal forcing. The first term on the rhs represents a windforced Kelvin mode that travels at a speed $C_{K}$, the second term is due to the westward-traveling Rossby wave of speed $C_{R}$ excited by the wind at time $t-\left[L / C_{K}+\right.$ $\left.L /\left(2 C_{R}\right)\right]$ and reflected as a Kelvin wave. The nonlinear function $A(h)$ relates wind stress to SST and SST to thermocline depth, and reflects the nonuniform stratification of the ocean. The slope of $A(h)$ at $h=0$, set by the parameter $\kappa$, is a measure of the strength of the coupling between ocean and atmosphere, as shown:

$$
\begin{aligned}
\dot{h}= & \tau_{1} A\left[h\left(t-\frac{L}{2 C_{K}}\right)\right]-\tau_{2} A\left[h\left(t-\frac{L}{C_{K}}+\frac{L}{2 C_{R}}\right)\right] \\
& +\tau_{3} \cos \omega(t-\delta) \text { and }
\end{aligned}
$$

We employ the one-way linkage between the L84 equations and the ENSO model shown in Eqs. (A12)-(A14), which represents the direct influence of El Niño on jet stream and eddy strength through atmospheric pathways:

$$
\begin{aligned}
\dot{X}= & -Y^{2}-Z^{2}-\alpha X+\alpha\left\{F_{0}+F_{1} \cos \left(\omega_{\alpha} t\right)\right. \\
& \left.+a_{n x} T_{ \pm} \tanh \left[c_{ \pm} h\left(t-t_{X}\right)\right]\right\} \\
\dot{Y}= & X Y-b X Z-Y+G_{0}+G_{1} \cos \left(\omega_{\alpha} t\right) \\
& +a_{n y} T_{ \pm} \tanh \left(c_{ \pm} h\right), \text { and } \\
\dot{Z}= & b X Y+X Z-Z .
\end{aligned}
$$

We explore two different coupling approaches, motivated by the observational analysis in section 2 : (i) delayed forcing of the midlatitude mean zonal wind $X$ by ENSO through EPG: $a_{n x} T_{ \pm} \tanh \left[c_{ \pm} h\left(t-t_{X}\right)\right]$ and (ii) forcing of the midlatitude eddies $Y, Z$ by ENSO through the OLC: $a_{n y} T_{ \pm} \tanh \left(c_{ \pm} h\right)$.

The term $T_{ \pm} \tanh \left[c_{ \pm} h\left(t-t_{X}\right)\right]$ represents the tropical SST anomaly, where the parameters $T_{+}\left(T_{-}\right)$and $c_{+}$ $\left(c_{-}\right)$are associated with positive (negative) thermocline depth anomalies $h$ given by Eq. (A10). We consider two months for the lagged response of midlatitude circulation to the tropical Pacific conditions $\left(t_{X}=2\right)$, based on the cross correlation between the Niño-3 index and the EPG. Figures 6 and 7 show that the effect of ENSO on the EPG and OLC exhibits strong seasonality. In this model, the coupling coefficients $a_{n x}$ and $a_{n y}$ do not vary seasonally; therefore, the above-mentioned seasonality is expressed only via the seasonal changes in the ENSO signal amplitude represented by the ENSO model. Regression of the EPG and OLC time series on the Niño-3 record provides coupling parameters $a_{n x}=0.00513$ and $a_{n y}=-0.184$. The $F$ and $G$ parameters are computed in such a way that the terms $\left\{F_{0}+F_{1} \cos \left(\omega_{\alpha} T\right)+\right.$ $\left.a_{n x} T_{ \pm} \tanh \left[c_{ \pm} h\left(t-t_{X}\right)\right]\right\}$ and $\left[G_{0}+G_{1} \cos \left(\omega_{\alpha} T\right)+\right.$ $\left.a_{n y} T_{ \pm} \tanh \left(c_{ \pm} h\right)\right]$ equal the summer and winter values of $F$ and $G$, respectively. The values of all other parameters, which are adopted from Lorenz (1984), Tziperman et al. (1994), Munnich et al. (1991), and Cane and Zebiak (1985), are given in Table A1.

\section{f. Significance test of bivariate pdf changes}

To assess the significance of the difference between 20-yr periods of the joint pdf of the EPG and OLC, 
TABLE A1. Parameter values for the ENSO-forced L84 model.

\begin{tabular}{lllc}
\hline \hline$\alpha$ & 0.25 & $\tau_{1}$ & $(180 \text { days })^{-1}$ \\
$b$ & 4.0 & $\tau_{2}$ & $(120 \text { days })^{-1}$ \\
$C_{K}$ & $L /(2.3$ months $)$ & $\tau_{3}$ & $(138 \text { days })^{-1}$ \\
$C_{R}$ & $C_{K} / 3$ & $\delta$ & 6 months \\
$T_{+}$ & 11 & $c_{+}$ & 0.8 \\
$T_{-}$ & 2 & $c_{-}$ & 1.9 \\
$a_{+}$ & 1 & $b_{+}$ & 1.5 \\
$a_{-}$ & 1 & $b_{-}$ & $b_{+} / 5$ \\
$\kappa$ & 2.0 & $t_{X}$ & 2 months \\
$a_{n x}$ & 0.00513 & $a_{n y}$ & -0.184 \\
\hline
\end{tabular}

presented in section 2, we perform the following significance test.

The null hypothesis is that any random 20 -yr sample from the record is drawn from the same population. We consider two random samples, $i$ and $j$, from the EPG and OLC record, both of length $n=20 \mathrm{yr}$. We estimate the joint probability density function $f_{i}(\mathrm{EPG}, \mathrm{OLC})$ using local polynomial estimation Locfit (Loader 1999). We define $L_{i j}$ as the likelihood that sample $i$ could have been generated by the same process that generated sample $j$ :

$$
L_{i j}=e^{\sum_{t=1}^{n}\left\{\log \left[f_{i}\left(\mathrm{EPG}_{j t}, \mathrm{OLC}_{j t}\right)\right] / n\right\}}
$$

If the likelihood is high, then the two samples belong to the same underlying population. Conversely, if it is low, then the null hypothesis of the common generating mechanism would be rejected.

This observation suggests that a one-sided significance test that assesses whether $L_{i j}>L^{a}$, where $L^{a}$ is the $a$ th percentile of the sampling distribution of $L_{i j}$, is needed. To determine the significance level, we calculate the likelihoods $L_{i j}$ of randomly drawn 20-yr samples 1000 times and define the significance level to be the 10th percentile of the likelihood values obtained from the 1000 experiments, namely, 0.45 .

For each one of the 20-yr periods shown in Fig. 5, we compute the likelihood of its belonging to the same population as any of the other 20 -yr periods and show

TABLE A2. The likelihood $L_{i j}$ of 20-yr-period joint pdfs being the same. Boldface values indicate pdfs that could not be drawn from the same population at the $10 \%$ significance level, because both $L_{i j}$ and $L_{j i}$ (boldface) or at least one of them (italic) rejects the null hypothesis.

\begin{tabular}{lccccc}
\hline \hline & $1900-20$ & $1920-40$ & $1940-60$ & $1960-80$ & $1980-2000$ \\
\hline $1900-20$ & - & $\mathbf{0 . 0 3}$ & $\mathbf{0 . 2 7}$ & $\mathbf{0 . 0 8}$ & $\mathbf{0 . 1 7}$ \\
$1920-40$ & $\mathbf{0 . 1 4}$ & - & 1.49 & $\mathbf{0 . 0 1}$ & $\mathbf{0 . 0 0}$ \\
$1940-60$ & $\mathbf{0 . 4 3}$ & 0.32 & - & 0.47 & 0.40 \\
$1960-80$ & $\mathbf{0 . 3 4}$ & $\mathbf{0 . 0 2}$ & 0.94 & - & 1.23 \\
$1980-2000$ & $\mathbf{0 . 0 0}$ & $\mathbf{0 . 0 5}$ & 0.66 & 0.70 & - \\
\hline
\end{tabular}

TABLE A3. As in Table A2, but for the pdf's with respect to ENSO state.

\begin{tabular}{lccc}
\hline \hline & El Niño (warm) & La Niña (cold) & Neutral \\
\hline El Niño (warm) & - & 0.81 & $\mathbf{0 . 9 5}$ \\
La Niña (cold) & 1.25 & - & 1.47 \\
Neutral & $\mathbf{0 . 7 7}$ & 1.19 & - \\
\hline
\end{tabular}

the results in Table A2. Under the null hypothesis that samples $i$ and $j$ are generated by the same process, both $L_{i j}$ and $L_{j i}$ should be above the significance level. Boldface numbers indicate the values that are below the significance level, that is, fail the test and indicate that the two joint pdfs are distinguishable and could not come from the same population. The results indicate that the pdfs in the first half of the century are significantly different from the pdfs in the second half.

We performed the same test to estimate the significance of the changes in the pdf of the EPG and OLC with respect to ENSO events. Table A3 shows the likelihood estimates. Boldface numbers indicate that the two pdfs could not be drawn from the same population at the $10 \%$ significance level. The results indicate that the pdf during El Niño events is significantly different from the pdfs during La Niña and neutral years. The similarity of the pdfs between La Niña and neutral events is to be expected, given that La Niña conditions are closer to the normal state of the equatorial Pacific.

\section{REFERENCES}

Barnes, E., D. L. Hartmann, D. M. W. Frierson, and J. Kidston, 2010: Effect of latitude on the persistence of eddy-driven jets. Geophys. Res. Lett., 37, L11804, doi:10.1029/2010GL043199.

Barnett, T., D. Pierce, M. Latif, D. Dommenget, and R. Saravanan, 1999: Interdecadal interactions between the tropics and the mid-latitudes in the Pacific basin. Geophys. Res. Lett., 26, 615-618.

Brayshaw, D. J., B. Hoskins, and M. Blackburn, 2008: The stormtrack response to idealized SST perturbations in an aquaplanet GCM. J. Atmos. Sci., 65, 2842-2860.

Broer, H., C. Simó, and R. Vitolo, 2002: Bifurcations and strange attractors in the Lorenz-84 climate model with seasonal forcing. Nonlinearity, 15, doi:10.1088/0951-7715/15/4/312.

Brohan, P., J. J. Kennedy, I. Harris, S. F. B. Tett, and P. D. Jones, 2006: Uncertainty estimates in regional and global observed temperature changes: A new data set from 1850. J. Geophys. Res., 111, D12106, doi:10.1029/2005JD006548.

Butler, A. H., D. W. J. Thompson, and T. Birner, 2011: Isentropic slopes, downgradient eddy fluxes, and the extratropical atmospheric circulation response to tropical tropospheric heating. J. Atmos. Sci., 68, 2292-2305.

Cai, W., and P. Chu, 1998: Oceanic responses to gradual transitions of equator-to-pole temperature gradients. Quart. J. Roy. Meteor. Soc., 124, 2817-2828.

Cane, M., and S. Zebiak, 1985: A model El Niño-Southern Oscillation. Science, 228, 1085. 
Freire, J. G., C. Bonatto, C. C. DaCamara, and J. A. C. Gallas, 2008: Multistability, phase diagrams, and intransitivity in the Lorenz-84 low-order atmospheric circulation model. Chaos, 18, 033121, doi:10.1063/1.2953589.

Gerber, E., and G. Vallis, 2007: Eddy-zonal flow interactions and the persistence of the zonal index. J. Atmos. Sci., 64, 32963311.

Gu, D., and S. Philander, 1997: Interdecadal climate fluctuations that depend on exchanges between the tropics and the extratropics. Science, 275, 805-807.

Hansen, J., M. Sato, R. Ruedy, K. Lo, D. Lea, and M. MedinaElizade, 2006: Global temperature change. Proc. Natl. Acad. Sci. USA, 103, 14 288-14 293, doi:10.1073/pnas.0606291103.

Hernández-Deckers, D., and J.-S. von Storch, 2011: The energetics response to a warmer climate: Relative contributions from the transient and stationary eddies. Earth Syst. Dyn., 2, 105-120.

Hoerling, M., and M. Ting, 1994: Organization of extratropical transients during El Niño. J. Climate, 7, 745-766.

$\longrightarrow, \ldots$, and A. Kumar, 1995: Zonal flow-stationary wave relationship during El Niño: Implications for seasonal forecasting. J. Climate, 8, 1838-1852.

Holton, J., 2004: An Introduction to Dynamic Meteorology. 4th ed. Elsevier Academic Press, 535 pp.

Inatsu, M., H. Mukougawa, and S.-P. Xie, 2003: Atmospheric response to zonal variations in midlatitude SST: Transient and stationary eddies and their feedback. J. Climate, 16, 33143329.

Jain, S., 1998: Low-frequency climate variability: Inferences from simple models. M.S. thesis, Dept. of Civil and Environmental Engineering, Utah State University, 187 pp.

_, U. Lall, and M. E. Mann, 1999: Seasonality and interannual variations of North Hemisphere temperature: Equator-topole gradient and ocean-land contrast. J. Climate, 12, 10861100 .

Jones, P. D., and K. R. Briffa, 1992: Global surface air temperature variations during the twentieth century: Part 1, spatial, temporal, and seasonal details. Holocene, 2, 165-179.

Joseph, R., M. Ting, and P. J. Kushner, 2004: The global stationary wave response to climate change in a coupled GCM. J. Climate, 17, 540-556.

Kalnay, E., and Coauthors, 1996: The NCEP/NCAR 40-Year Reanalysis Project. Bull. Amer. Meteor. Soc., 77, 437-471.

Kaplan, A., M. Cane, Y. Kushnir, A. Clement, M. Blumenthal, and B. Rajagopalan, 1998: Analyses of global sea surface temperature 1856-1991. J. Geophys. Res., 103 (C9), 567-589.

Kidston, J., D. Frierson, J. Renwick, and G. Vallis, 2010: Observations, simulations, and dynamics of jet stream variability and annular modes. J. Climate, 23, 6186-6199.

Kleeman, R., J. McCreary, and B. Klinger, 1999: A mechanism for generating ENSO decadal variability. Geophys. Res. Lett., 26, 1743-1746.

Kumar, A., and M. Hoerling, 1995: Prospects and limitations of seasonal atmospheric GCM predictions. Bull. Amer. Meteor. Soc., 76, 335-345.

— A. Leetmaa, and M. Ji, 1994: Simulations of atmospheric variability induced by sea surface temperatures and implications for global warming. Science, 266, 632-634.

Lindzen, R. S., 1994: Climate dynamics and global change. Annu. Rev. Fluid Mech., 26, 353-378.

—, and W. Pan, 1994: A note on orbital control of equator-pole heat fluxes. Climate Dyn., 10, 49-57.

Loader, C., 1999: Local Regression and Likelihood. Statistics and Computing Series, Springer, 290 pp.
Lorenz, D. J., and E. T. DeWeaver, 2007: Tropopause height and zonal wind response to global warming in the IPCC scenario integrations. J. Geophys. Res., 112, D10119, doi:10.1029/ 2006JD008087.

Lorenz, E. N., 1982: Low-order models of atmospheric circulations. J. Meteor. Soc. Japan, 60, 255-267.

— 1984: Irregularity: A fundamental property of the atmosphere. Tellus, 36A, 98-100.

_ 1990: Can chaos and intransitivity lead to interannual variability? Tellus, 42A, 378-389.

Lu, J., G. Chen, and D. M. W. Frierson, 2008: Response of the zonal mean atmospheric circulation to El Niño versus global warming. J. Climate, 21, 5835-5851.

$\longrightarrow,-$, and -2010 : The position of the midlatitude storm track and eddy-driven westerlies in aquaplanet AGCMs. J. Atmos. Sci., 67, 3984-4000.

Mann, M. E., and J. Park, 1996: Greenhouse warming and changes in the seasonal cycle of temperature: Model versus observations. Geophys. Res. Lett., 23, 1111-1114.

McPhaden, M. J., 2003: Tropical Pacific Ocean heat content variations and ENSO persistence barriers. Geophys. Res. Lett., 30, 1480, doi:10.1029/2003GL016872.

Mechoso, C., A. Kitoh, S. Moorthi, and A. Arakawa, 1987: Numerical simulations of the atmospheric response to a sea surface temperature anomaly over the equatorial eastern Pacific Ocean. Mon. Wea. Rev., 115, 2936-2956.

Meehl, G. A., W. M. Washington, C. M. Ammann, J. M. Arblaster, T. M. L. Wigley, and C. Tebaldi, 2004: Combinations of natural and anthropogenic forcings in twentieth-century climate. J. Climate, 17, 3721-3727.

Müller, W., and E. Roeckner, 2008: ENSO teleconnections in projections of future climate in ECHAM5/MPI-OM. Climate Dyn., 31, 533-549.

Munnich, M., M. A. Cane, and S. E. Zebiak, 1991: A study of selfexcited oscillations of the tropical ocean-atmosphere system. Part II: Nonlinear cases. J. Atmos. Sci., 48, 1238-1248.

O'Gorman, P. A., and T. Schneider, 2008: Energy of midlatitude transient eddies in idealized simulations of changed climates. J. Climate, 21, 5797-5806.

Palmer, T., 2005: Global warming in a nonlinear climate - Can we be sure? Europhys. News, 36, 42-46.

_ anomalies during past El Niño events using a high resolution general circulation model. I: Influence of model climatology. Quart. J. Roy. Meteor. Soc., 112, 613-638.

$\longrightarrow$, and $1986 \mathrm{~b}$ : A study of wintertime circulation anomalies during past El Niño events using a high resolution general circulation model. II: Variability of the seasonal mean response. Quart. J. Roy. Meteor. Soc., 112, 639-660.

_ , F. Doblas-Reyes, R. Hagedorn, and A. Weisheimer, 2005: Probabilistic prediction of climate using multi-model ensembles: From basics to applications. Philos. Trans. Roy. Soc. London, B360, 1991-1998.

Reynolds, R., N. Rayner, T. Smith, D. Stokes, and W. Wang, 2002: An improved in situ and satellite SST analysis for climate. J. Climate, 15, 1609-1625.

Roebber, P. J., 1995: Climate variability in a low-order coupled atmosphere-ocean model. Tellus, 47A, 473-494.

_ 2009: Planetary waves, cyclogenesis, and the irregular breakdown of zonal motion over the North Atlantic. Mon. Wea. Rev. 137, 3907-3917.

— A. A. Tsonis, and J. B. Elsner, 1997: Do climate simulations from models forced by averaged sea surface temperatures 
represent actual dynamics? Nonlinear Processes Geophys., 4, 93-100.

Ropelewski, C., and M. Halpert, 1987: Global and regional scale precipitation patterns associated with the El Niño/Southern Oscillation. Mon. Wea. Rev., 115, 1606-1626.

Seager, R., N. Harnik, Y. Kushnir, W. Robinson, and J. Miller, 2003: Mechanisms of hemispherically symmetric climate variability. J. Climate, 16, 2960-2978.

Simonnet, E. R., H. A. Dijkstra, and M. Ghil, 2009: Bifurcation analysis of ocean, atmosphere, and climate models. Computational Methods for the Atmosphere and the Oceans, R. M. Temam and J. J. Tribbia, Eds., Handbook of Numerical Analysis, Vol. 14, 187-229.

Strong, C., and R. Davis, 2008: Variability in the position and strength of winter jet stream cores related to Northern Hemisphere teleconnections. J. Climate, 21, 584-592.

Thomson, D. J., 1995: The seasons, global temperature, and precession. Science, 268, 59-68.

Tziperman, E., L. Stone, M. A. Cane, and H. Jarosh, 1994: El Niño chaos: Overlapping of resonances between the seasonal cycle and the Pacific ocean-atmosphere oscillator. Science, 264, $72-74$.

van Veen, L., 2003: Baroclinic flow and the Lorenz-84 model. Int. J. Bifurcation Chaos Appl. Sci. Eng., 13, 2117-2139.

_, T. Opsteegh, and F. Verhulst, 2001: Active and passive ocean regimes in a low-order climate model. Tellus, 53A, 616-628.

Wang, C., 2004: ENSO, Atlantic climate variability, and the Walker and Hadley circulations. The Hadley Circulation: Present, Past and Future, H. F. Diaz and R. S. Bradley, Eds., Advances in Global Change Research, Vol. 21, 173-202.

Wild, M., and Coauthors, 2005: From dimming to brightening: Decadal changes in solar radiation at earth's surface. Science, 308, 847-850.

Xue, Y., A. Leetmaa, and M. Ji, 2000: ENSO prediction with Markov models: The impact of sea level. J. Climate, 13, 849-871.

Yin, J. H., 2005: A consistent poleward shift of the storm tracks in simulations of 21 st century climate. Geophys. Res. Lett., 32, L18701, doi:10.1029/2005GL023684.

Zebiak, S. E., and M. A. Cane, 1987: A model of El Niño-Southern Oscillation. Mon. Wea. Rev., 115, 2262-2278. 